\title{
Serpin genes AtSRP2 and AtSRP3 are required for normal growth sensitivity to a DNA alkylating agent in Arabidopsis Joon-Woo Ahn1, Brian J Atwell ${ }^{2}$ and Thomas H Roberts*1
} \author{
Biological Sciences, Macquarie University, North Ryde NSW 2109, Australia \\ Email: Joon-Woo Ahn - joon-woo.ahn@students.mq.edu.au; Brian J Atwell - batwell@rna.bio.mq.edu.au; \\ Thomas H Roberts* - troberts@cbms.mq.edu.au \\ * Corresponding author
}

Address: ${ }^{1}$ Department of Chemistry and Biomolecular Sciences, Macquarie University, North Ryde NSW 2109, Australia and ${ }^{2}$ Department of

Published: II May 2009

BMC Plant Biology 2009, 9:52 doi:10.1 186/147|-2229-9-52
Received: 15 December 2008

Accepted: II May 2009

This article is available from: http://www.biomedcentral.com/I47/-2229/9/52

(c) 2009 Ahn et al; licensee BioMed Central Ltd.

This is an Open Access article distributed under the terms of the Creative Commons Attribution License (http://creativecommons.org/licenses/by/2.0), which permits unrestricted use, distribution, and reproduction in any medium, provided the original work is properly cited.

\begin{abstract}
Background: The complex responses of plants to DNA damage are incompletely understood and the role of members of the serpin protein family has not been investigated. Serpins are functionally diverse but structurally conserved proteins found in all three domains of life. In animals, most serpins have regulatory functions through potent, irreversible inhibition of specific serine or cysteine proteinases via a unique suicide-substrate mechanism. Plant serpins are also potent proteinase inhibitors, but their physiological roles are largely unknown.
\end{abstract}

Results: Six Arabidopsis genes encoding full-length serpins were differentially expressed in developing seedlings and mature tissues. Basal levels of AtSRP2 (At2gl4540) and AtSRP3 (Atlg64030) transcripts were highest in reproductive tissues. AtSRP2 was induced 5-fold and AtSRP3 100-fold after exposure of seedlings to low concentrations of methyl methanesulfonate (MMS), a model alkylating reagent that causes DNA damage. Homozygous T-DNA insertion mutants atsrp2 and atsrp3 exhibited no differential growth when mutant and wild-type plants were left untreated or exposed to $\gamma$-radiation or ultraviolet light. In contrast, atsrp2 and atsrp3 plants exhibited greater root length, leaf number and overall size than wild-type plants when exposed to MMS. Neither of the two serpins was required for meiosis. GFP-AtSRP2 was localized to the nucleus, whereas GFP-AtSRP3 was cytosolic, suggesting that they target different proteinases. Induction of cell cycle- and DNA damage-related genes AtBRCAI, AtBARDI, AtRAD5I, AtCYCBI; I and $A t C Y C D I ; I$, but not AtATM, was reduced relative to wild-type in atsrp2 and atsrp3 mutants exposed to MMS.

Conclusion: Expression of specific serpin genes (AtSRP2 and AtSRP3 in Arabidopsis) is required for normal responses of plants following exposure to alkylating genotoxins such as MMS.

\section{Background}

DNA damage results from exposure to specific chemicals in the environment, UV light, ionizing radiation and errors in DNA replication and proofreading. Plants utilize several pathways for DNA repair, including photoreactiva- tion, nucleotide excision repair, base excision repair, mismatch repair and double-stranded break repair [1]. Methyl methanesulfonate (MMS) is a simple, direct alkylating agent recognized as a standard for genotoxicity assays of environmental pollutants [2]. MMS has been 
widely utilized as a $\gamma$-radiation mimic in the belief it causes double-stranded breaks (DSBs). A recent report found, however, that no MMS-mediated DSBs could be detected in vivo in yeast or mammalian cells, and those reported previously were almost certainly artefacts [3]. Molecular responses of organisms to alkylating phytotoxins are likely to be distinct from those to ionizing radiation.

Many intra- and extracellular processes in plant growth, development and responses to stress involve specific proteolytic enzyme activities. The Arabidopsis genome contains 656 known and putative peptidases [4] but the functions of only a tiny minority are known. Furthermore, little is known of the control of proteolytic activity in planta by endogenous peptidase inhibitors, including the serpins $[5,6]$, which are one of seven families of peptidase inhibitors in Arabidopsis [4]. Serpins are metastable inhibitors with a unique, irreversible mechanism of action [7].

Almost all plant serpins studied are potent inhibitors of mammalian proteinases of the chymotrypsin family in vitro [8-12]. An Arabidopsis serpin, AtSerpin1 (At1g47710), was shown to inhibit the endogenous cysteine proteinase Metacaspase 9 (AtMC9) in vitro [11] but no other putative endogenous targets for plant serpins have been identified. Plant serpins are likely to function in direct defence against proteinases from pests and pathogens and in the regulation of endogenous proteolytic events, but no functions have been demonstrated $[5,6]$.

Here we report the differential basal expression of six Arabidopsis serpin genes and the effect of MMS exposure of seedlings on the activity of AtSRP2 (At2g14540) and AtSRP3 (At1g64030), both specifically expressed in reproductive tissues. We determine the subcellular localizations of AtSRP2 2 and AtSRP3 and examine the growth responses of atsrp2 and atsrp3 mutants (vs wild-type) to MMS, $\gamma$-radiation and UV light treatments. Finally we compare the induction levels of cell cycle-related genes in the atsrp2 and atsrp3 plants compared to wild-type after exposure to MMS.

\section{Results}

\section{Arabidopsis serpin genes are differentially expressed}

PSI-BLAST searching of the Arabidopsis genome revealed six predicted full-length serpins ( $340-440$ residues) [6]. The numbering system used for the RCL residues is that of Schechter and Berger (1967) whereby residues N-terminal to the proteinase cleavage site are numbered P1, P2, P3, etc and those $\mathrm{C}$-terminal to the cleavage site are numbered P1', P2', P3', etc [13]. Reactive centre loop (RCL) sequences were aligned using the conserved P17 Glu, P14 Thr and P8 Ser/Thr, allowing the reactive centre P1 residue - the most important for inhibitory specificity - to be identified for each serpin (Figure 1). One of the Arabidopsis serpins (At1g62170) was predicted to be non-inhibitory (based on P10 Thr and P11 Val) but each of the five remaining serpins was predicted to be inhibitory [5] and has a unique reactive centre (Figure 1).

We examined basal transcript levels of the six serpins in mature tissues and in whole seedlings during development using semi-quantitative RT-PCR. AtSerpin1 (At1g47710) was the most highly expressed serpin in all tissues (Figure 2A). This gene and At2g26390 were ubiquitously expressed in the mature plants. In contrast, AtSRP2 and AtSRP3 transcripts were detected more specifically in siliques, with AtSRP2 also expressed very weakly in flowers and AtSRP3 in flowers and stems. At3g45220 and At1g62170 expression was not detectable in mature tissues. AtSerpin1 was ubiquitously expressed throughout seedling development (Figure 2B). Weak expression of At2g26390 was detected at day 2 and increased during days 4 to 8 . At3g45220 and At1g62170 expression was not detectable in seedlings. AtSRP2 and AtSRP3 transcripts were detected at very low levels in seedlings $(5 \mathrm{~d})$ by quantitative RT-PCR (data not shown).

\section{AtSRP2 and AtSRP3 are upregulated following MMS treatment of seedlings}

Wild-type (5-d) seedlings were transplanted to liquid media containing 200 ppm MMS and transcript levels of AtSRP2 and AtSRP3 determined by quantitative RT-PCR. AtSRP2 and AtSRP3 were induced $\sim 5$-fold and 100-fold, respectively, after $2 \mathrm{~d}$ (Figure 2C). In a separate experiment, wild-type seedlings (5-d) were exposed to MMS for 1 and $3 \mathrm{~h}$ but no induction was detected. In untreated seedlings (5-d) and in seedlings 1 and $3 \mathrm{~h}$ after exposure to $\gamma$-radiation (125 Gy) no AtSRP2 and AtSRP3 transcripts were detected using semiquantitative RT-PCR (data not shown).

\section{Subcellular localization of AtSRP2 and AtSRP3}

GFP-AtSRP2 was localized to the nucleus whereas GFPAtSRP3 was localized to the cytosol (as was GFP alone, as expected) (Figure 2D). DAPI staining confirmed the identity of the nucleus.

\section{Identification of T-DNA insertion mutants}

Two T-DNA insertion mutants (SALK_088095 and SALK_072458) corresponding to AtSRP2 and AtSRP3, respectively, were identified in the SIGnAl database. No other T-DNA insertion lines were available for these two genes. The atsrp2 and atsrp 3 mutants have a T-DNA insertion on the right (Figure $3 \mathrm{~A}$ ) and in the middle (Figure 3B) of the second exon, respectively. Genomic PCR using primer sets corresponding to the $5^{\prime}$ and $3^{\prime}$ ends of each gene and to the left border of the T-DNA insert was performed to identify homozygous lines. The absence of full- 


\begin{abstract}
AtSerpin1 At 1g62170 At SRP 3

At SRP 2

At 2926390

At 3945220

AtSerpin1 At 1962170 At SRP 3

At SRP2

At 2926390

At 3945220

AtSerpin1 At 1962170 At SRP 3

AtSRP 2

At 2926390

At 3945220

AtSerpin1 At 1962170 At SRP 3

At SRP 2

At2g26390

At 3945220

AtSerpin1 At1g62170 At SRP 3

At SRP 2

At2g26390

At 3945220

MEPKEKKQKLD T SEVASP S L SKTHLKKKKTKKQKIRKS QE I T SP S L S KNTD LVIASP S L SI MDVRESISLQNQVSMNLAKHVITT-VSQNSNVIFSPASI IDVGEAMKKQNDVAIFLTGIVISS-VAKNSNFVFSPAS I REAMKNQTHVAMI LSGHVLSS-APKDSNVIFSPAS I IDMQEAMKNQNEVSLLLVGKVISA-VAKNSN VFSPAS I MELGKS IENQNNVVARLAKKVIETDVANGSNVVFSPMS I -MELGKSMENQTDVMVLLAKHVIPT-VANGSNLVFSPMS I

- $\quad$.

NVVLS I IAAGSAG----ATKDOILSFLKFSSTDOLNSFSSEIVSAVLADGSANGGPKLSVANGAWIDKSLSFKPSFKOLLEDSYKAASNOADFOSKAVEV NAALTMVAAS SGGEQGEELRSF ILSFLKS SSTDELNAIFREIASVVLVDGSKKGGPKIAVVNGMWMDQSLSVNPLSKDLFKNFF SAAFAQVDFRSKAEEV NSA I TMHAAGP GG---DLVSGQILSF LRSSS IDELKTVFRELASVVYADRSATGGPKITAANGLWIDKSLP TDP KFKDLFENFFKAVYVPVDFRSEAEEV NAVLTVTAANTDN---KTLRSF I LSFLKSSSTEETNA IFHELASVVFKDGSETGGPKIAAVNGVWMEQSLS NPDWEDLFLNFFKASFAKVDFRHKAEEV NVLLSLIAAGSNP----VTKEEILSFLMSP STDHLNAVLAKIA----DGGTERSDL LSTAHGVWIDKSSYLKP SEKELLENSYKAS SQVDFATKPVEV NVLL LIAAGSN ----VTKEQILSF IMLP SSDYLNAVLAKTVSVALNDGMERSDLHLSTAYGVWIDKSLSFKP SFKDLLENSYNAT NQVDFATKPAEV$$
\text { . . . . . . }
$$

IAEVNSWAEKETNGLITEVLPEGSADS-----MTKLIFANALYFKGTWNEKFDESLTQEGEFHLLDGNKVTAPFMTSKKKOYVSAYDGFKVLGLPYLQGQ RTEVNAWASSHTNGLIKDLLPRGSVTS-----LTDRVYGSALYFKGTWEEKYSKSMTK KPFYLLNGTSVSVPFMSSEEKQYIAAYDGEKVLRLPYRQGR RKEVNSWVEHHTNNLIKDLLPDGSVTS-----LTNKIYANALSFKGAWKRPFEKYYTRDNDFYLVNGT SVSVPFMS SYENQYVRAYDGFKVLRLPYQRGS RLDVNTWASRHTNDLIKEILPRGSVTS-----LTNWIYGNALYFKGAWEKAFDKSMTRDKPFHLLNGKSVSVPFMRSYEKQF IEAYDGFKVLRLPYRQGR IDEVNIWADVHTNGLIKQILSRD TDTIKEIRNSTLILANAVYFKAAWSRKFDAKLTKDNDF HLLDGNTVKVPFMMSYKDQYLRGYDGFQVLRLPYVE-INEVNAWAEVHTNGLIKEILSDDSIKT---IRESMLILANAVYFKGAWSKKFDAKLTKSYDFHLLDGTMVKVPFMTNYKKQYLEYYDGFKVLRLPYVE-$$
\text { • . . . . }
$$

--DKRQF SMYFYLPDANNGLSDLLDKIVSTPGF LDNHIPRRQVKVREFKIPKFKF SFGFDASNVLKGLGLTSPFSGEEGLTEMVESPEMGKNL - ---DNTNRNFAMY IYLP D KKGELDDLLERMTS TP GF LD S HNP ERRVKVGKFRIP KFKIEFGFEASSAF SDFELD--- - - - - - - - - - - - - - - - - - - DD TNRKF SMYFYLP DKKD GLDD LLEKMAS TP GF LD SH IP TYRDELEKFRIPKFKIEFGF SVT SVLDRLGLRS-- - - - - - - - - - - - - - - - - - DDTNREFSMYLYLPDKKGELDNLLERITSNPGFLDSHIPEYRVDVGDFRIPKFKIEFGFEASSVFNDFELN-

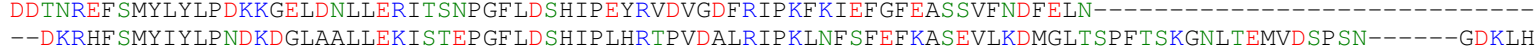
--DQRQFAMY IYLPNDRD GLP TLLEEISSKPRF LDNH IPRQRILTEAFKIPKFKFSEEFKASDVLKEMGLTLPFTH-GSLTEMVESPS IPENL VAENLF

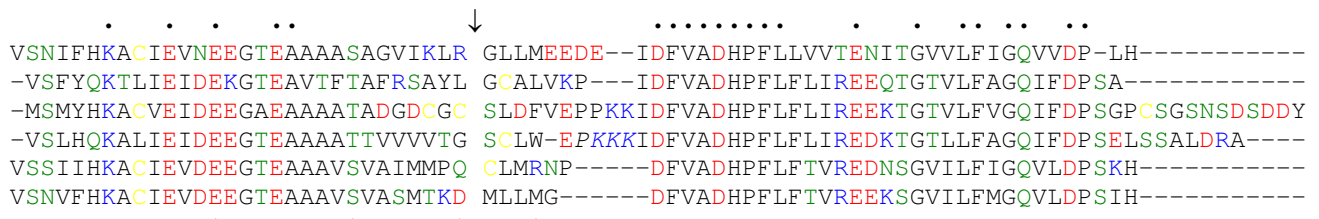
VSNVFHKA IEVDEEGTEAAAVSVASMTKD MLLMG------DFVADHPFLFTVREEKSGVILFMGQVLDPS IH-

$$
\text { P17 P8 P1 P4' }
$$
\end{abstract}

\title{
Figure I
}

Amino acid sequence alignment of full-length Arabidopsis serpins. The alignment was created using ClustalW and edited. Locus numbers are given for some of the serpins. Amino acid residues are colour-coded: positively charged, blue; negatively charged, red; polar, green; cysteine, yellow; other residues, black. Dots above the alignment indicate residues identical in all six serpins. Putative positions of specific residues in the RCL are indicated below the alignment: PI7 Glu, P8 Ser/Thr, PI (shown in bold) and P4'. A gap, indicated by an arrow, between the PI and PI' residues indicates the predicted site of proteinase cleavage. The predicted nuclear localization sequence for AtSRP3 is shown in bold italics. Large gaps in the sequences of the serpin at At Ig62170, AtSRP2 and AtSRP3 (second block from bottom, right side) represent lack of a surface loop lying between helix I and strand 5 of $\beta$-sheet $A$ (based on the human $\alpha_{1}$-antitrypsin structure); absence of this loop is not expected to affect folding to a metastable structure capable of inhibiting proteinases [5].

length PCR product using the $5^{\prime}$ and $3^{\prime}$ primer sets indicated the presence of the T-DNA insertion $(\sim 4 \mathrm{~kb})$ in both copies of the gene (Figure 3C and 3D). To confirm the knockout of each AtSRP2 and AtSRP3 transcript in the corresponding homozygous mutant, total RNA was prepared from developing siliques and RT-PCR performed. No transcripts for AtSRP2 and AtSRP3 were detected in the corresponding mutants, and there was no apparent compensation of AtSRP2 transcript levels in the atsrp3 mutant, or vice-versa (Figure 3E).

\section{atsrp2 and atsrp3 mutants grow faster than wild-type plants when exposed to MMS but not to -radiation or UV-C} Mutants atsrp2 and atsrp3 were phenotypically normal under standard growth conditions (Figure 3F). Both mutants produced apparently normal siliques, seeds (number and size), and wild-type germination rates (data not shown), indicating that AtSRP2 and AtSRP3 are not essential for meiosis under standard growth conditions. $1 / 2 \mathrm{MS}$ and B5 media were used to examine responses of mutants to MMS versus those of wild-type (similar results with both media). Surprisingly, when atsrp2 and atsrp3 plants were exposed to MMS, both mutants grew consistently more vigorously than wild-type plants given the same treatment (Figure 4A). In the absence of MMS, there was no significant difference in root growth between wildtype and mutants grown on solid media. For plants grown on B5 media in the presence of $\geq 55 \mathrm{ppm}$ MMS, however, roots of atsrp 2 and atsrp3 mutants grew longer than wildtype roots over 2 weeks (Figure 4B). Differences in root 
A

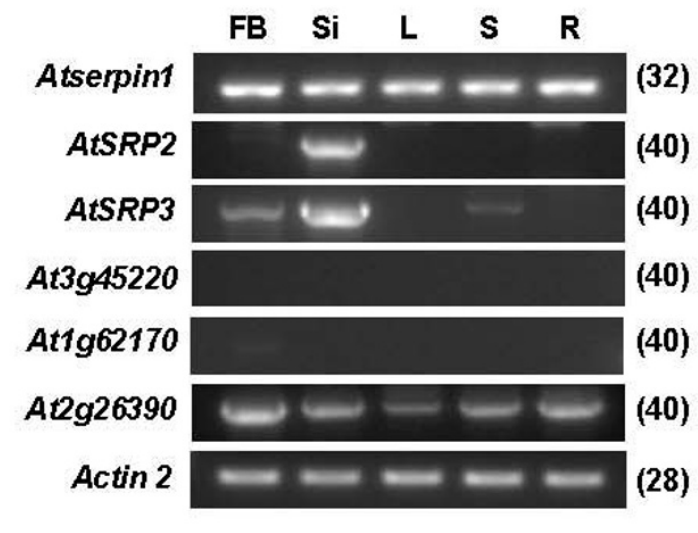

C

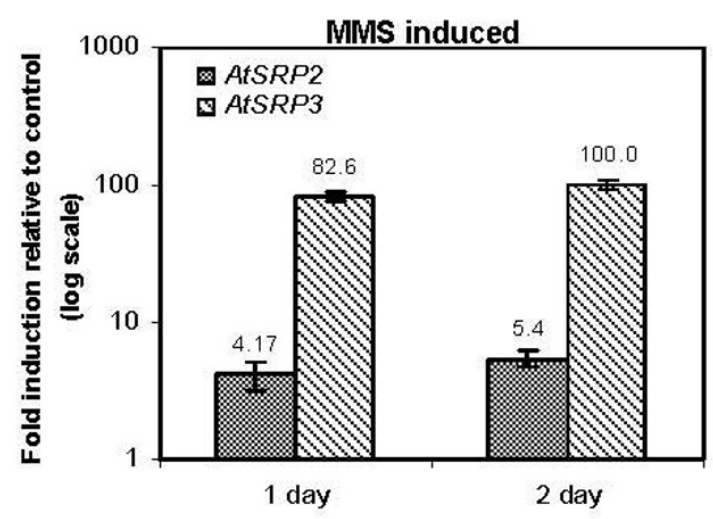

B
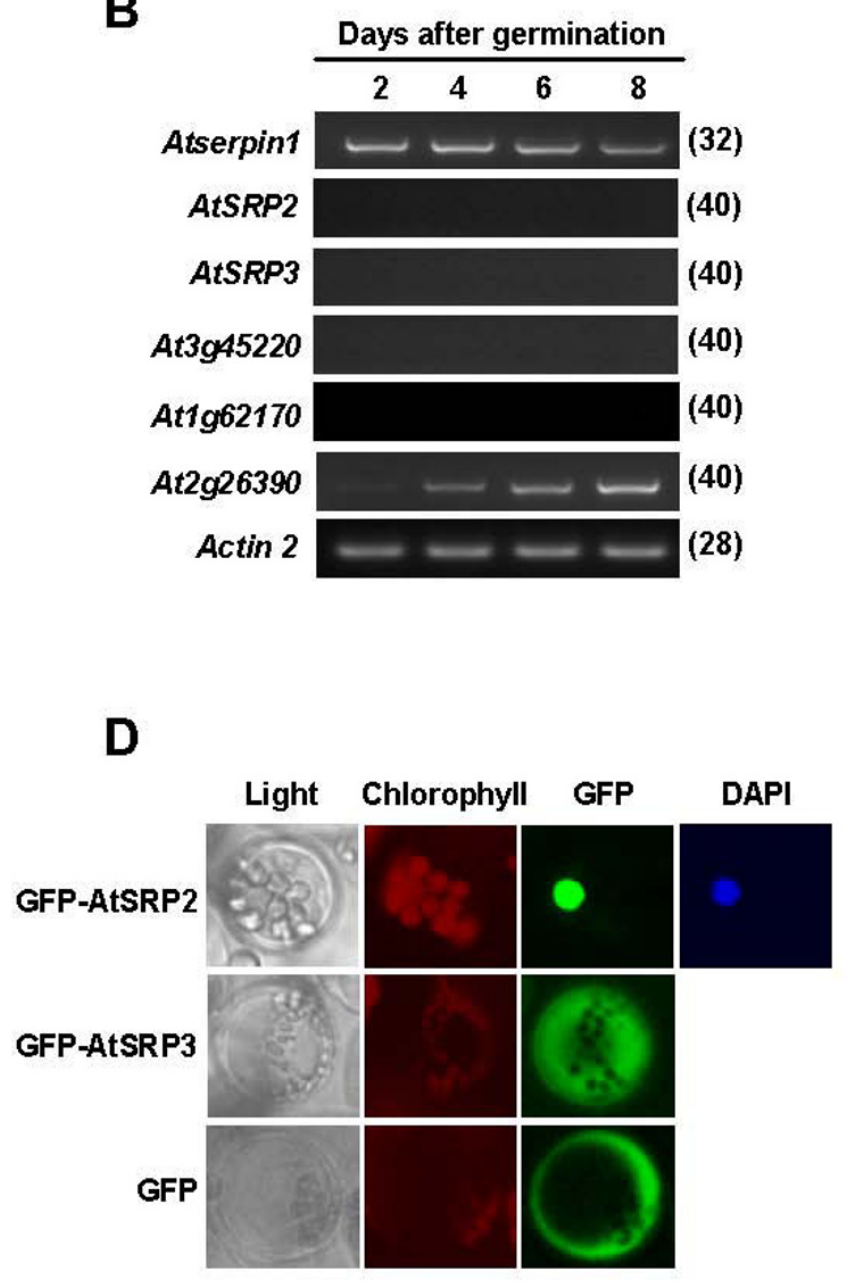

\section{Figure 2}

Expression of Arabidopsis serpin genes. (A, B) Semi-quantitative RT-PCR. Values in brackets indicate number of cycles. Actin2 served as a control. (A) Expression of serpin genes in mature tissues. RNA was extracted from 6-week-old plants. FB, flowers and flower buds; Si, siliques; L, leaves; S, stems; R, roots. (B) Expression of serpin genes in whole seedlings during early development (2-8 d). (C) Induction of AtSRP2 and AtSRP3 in response to MMS treatment of seedlings (5-d) after I and $2 \mathrm{~d}$ as determined by quantitative RT-PCR. Values are means +/- SE $(n=3)$. (D) Subcellular localization of AtSRP2 and AtSRP3. GFP fusion constructs with AtSRP2 and AtSRP3 full-length cDNAs, respectively, were transformed into Arabidopsis protoplasts. Bright-field, chlorophyll, GFP and DAPI-stained images are shown. Expression of GFP alone was a cytosolic marker. DAPI staining served as a marker for nuclear localization.

lengths between the mutants and wild-type seedlings grown on $1 / 2 \mathrm{MS}$ solid media were greatest at $40 \mathrm{ppm}$ MMS (Figure 4C). Leaf number was significantly higher in mutants than in wild-type seedlings exposed to $55 \mathrm{ppm}$ MMS on B5 solid media (Figure 4D) and this effect was accompanied by an increase in overall plant biomass (Figure 4E). We also examined the response of atsrp2 and atsrp3 mutants to UV light and $\gamma$-radiation, but no differential effects (vs. wild-type) could be detected (Figure 5A and 5B). RT-PCR using RNA isolated from whole seed- lings (5-d) exposed to $\gamma$-radiation showed expression levels of the DNA repair gene AtRAD51 were the same in the mutants and wild-type (Figure 5C).

Induction of DNA repair- and cell cycle-related genes is reduced in atsrp2 and atsrp3 mutants exposed to MMS After MMS treatment of seedlings grown on 1/2 MS liquid media, samples were collected at various time points, total RNA was isolated and real-time RT-PCR performed. In wild-type plants, exposure to 200 ppm MMS led to a sub- 

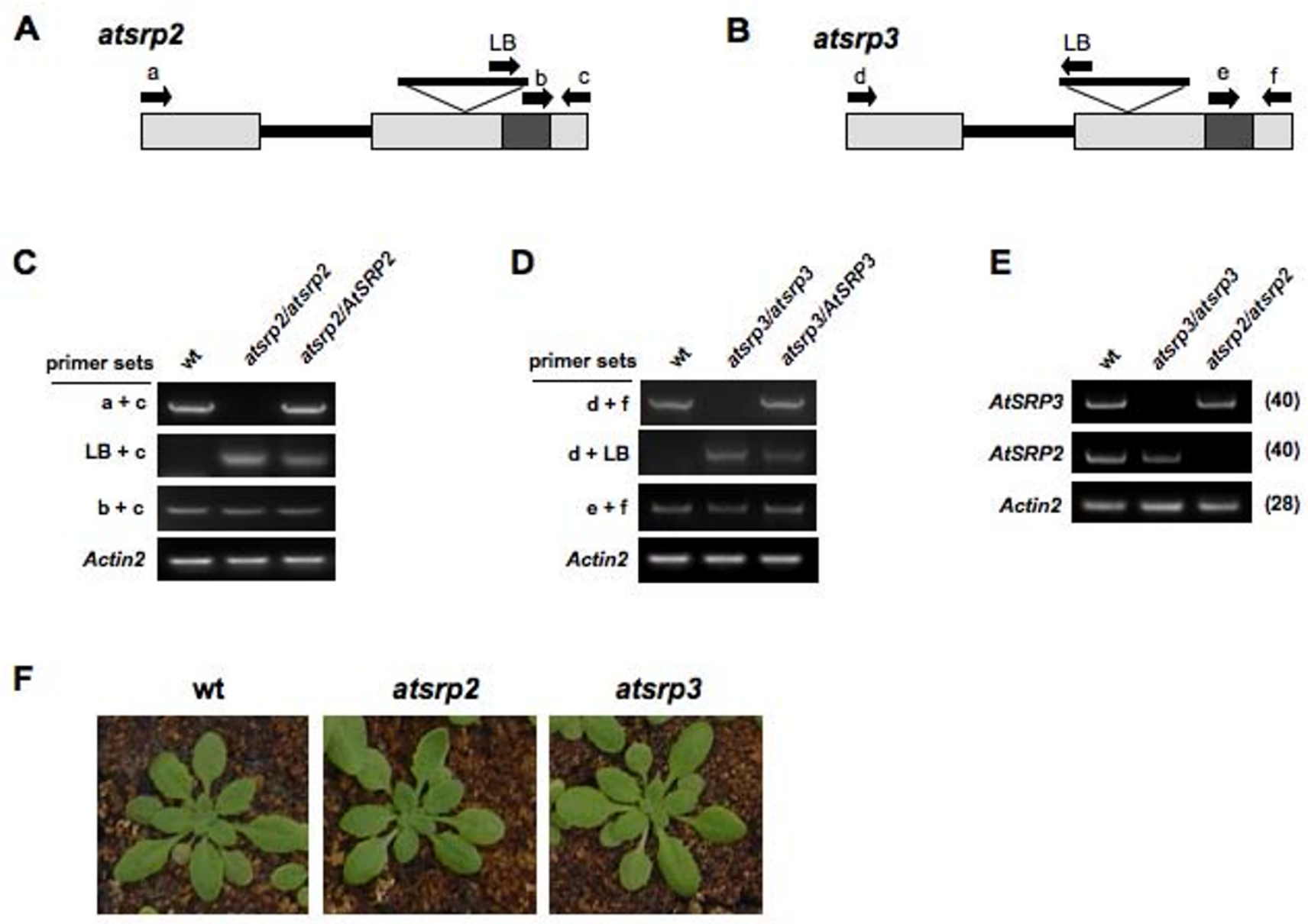

\section{Figure 3}

Schematic representations of atsrp2 and atsrp3 T-DNA insertion mutants and identification of homozygous lines. (A, B) Genomic sequences of AtSRP3 and AtSRP2 each contain two exons. Primers for screening of homozygous lines are indicated by letters a-f and LB (left border). Gray boxes indicate the RCL motif. (C, D) Genomic-PCR analysis for screening of homozygous lines using the primers shown in $A$ and $B$. wt, wild-type. (E) Confirmation of knockout of AtSRP2 and AtSRP3 expression in each mutant via semi-quantitative RT-PCR. RNA was isolated from developing siliques. Values in brackets indicate number of cycles. Actin2 served as a control. (F) Phenotype of atsrp2 and atsrp3 mutants. Mutants and wild-type plants were grown in a growth chamber at $24^{\circ} \mathrm{C}$. Photographs were taken at 4 weeks after sowing.

stantial induction after $1 \mathrm{~d}$ of all marker genes examined, with the exception of AtCYCD1;1, which was induced after $2 \mathrm{~d}$ (Figure 6B and 6C; compare to Figure 6A). Interestingly, for both atsrp2 and atsrp3 mutants, expression of all marker genes except AtATM was lower than that in wild-type plants $1 \mathrm{~d}$ after MMS treatment (Figure 6A-C). The cell-cycle related gene AtCYCD1;1 was down-regulated 1 day after plant exposure to MMS compared to both the zero time point and to wild-type levels (Fig. 6A-C). Recovery of the expression of all of the marker genes except AtCYCD1;1 to wild-type levels occurred by day 2 (Figure 6A-C). The rapid changes in expression of these key genes suggest AtSRP2 and AtSRP3 function in responses to DNA-damage after exposure to MMS.

\section{Discussion}

Diversity of Arabidopsis serpin reactive centres and differential expression

The reactive centres of the Arabidopsis serpins are highly diverse (Figure 1), suggesting a range of target proteinases and therefore distinct biochemical pathways in which the serpins might participate. The only specific target proteinase suggested for a plant serpin to date is the cysteine proteinase Metacaspase 9 (AtMC9) for AtSerpin1 [11]. Differential expression of the serpin genes (Figure 2A and 2B) is corroborated by AtProteome data [14] and provides more evidence for functional diversity. The nuclear localization of AtSRP2 is consistent with predictions [5] based on WoLF PSORT and contrasts with the cytosolic localization of AtSRP3 (Figure 2D). AtSRP2 contains the nuclear 
A
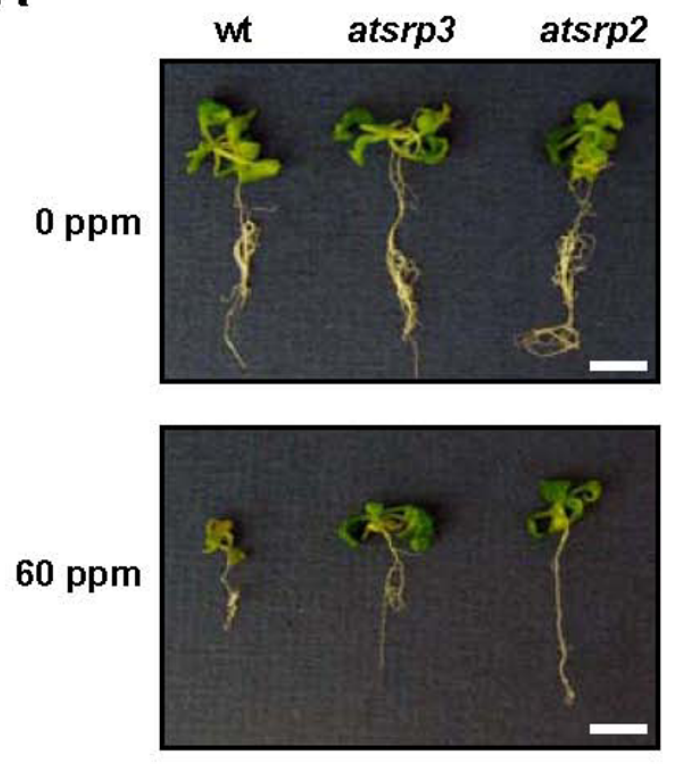

C

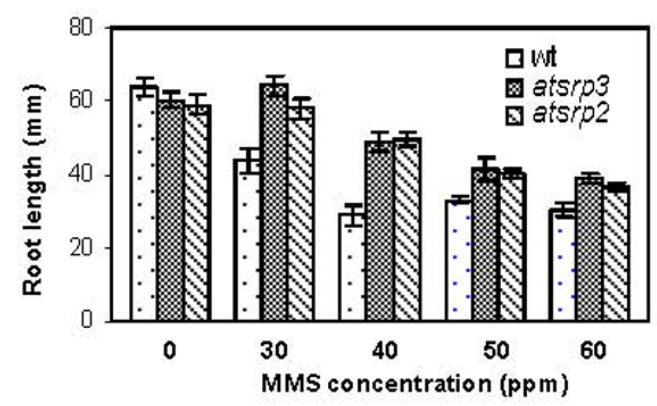

D

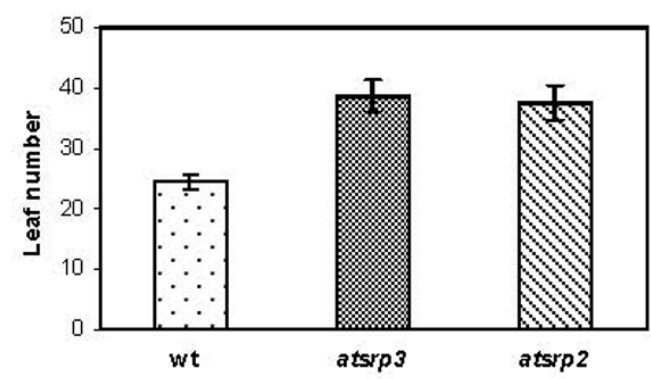

B

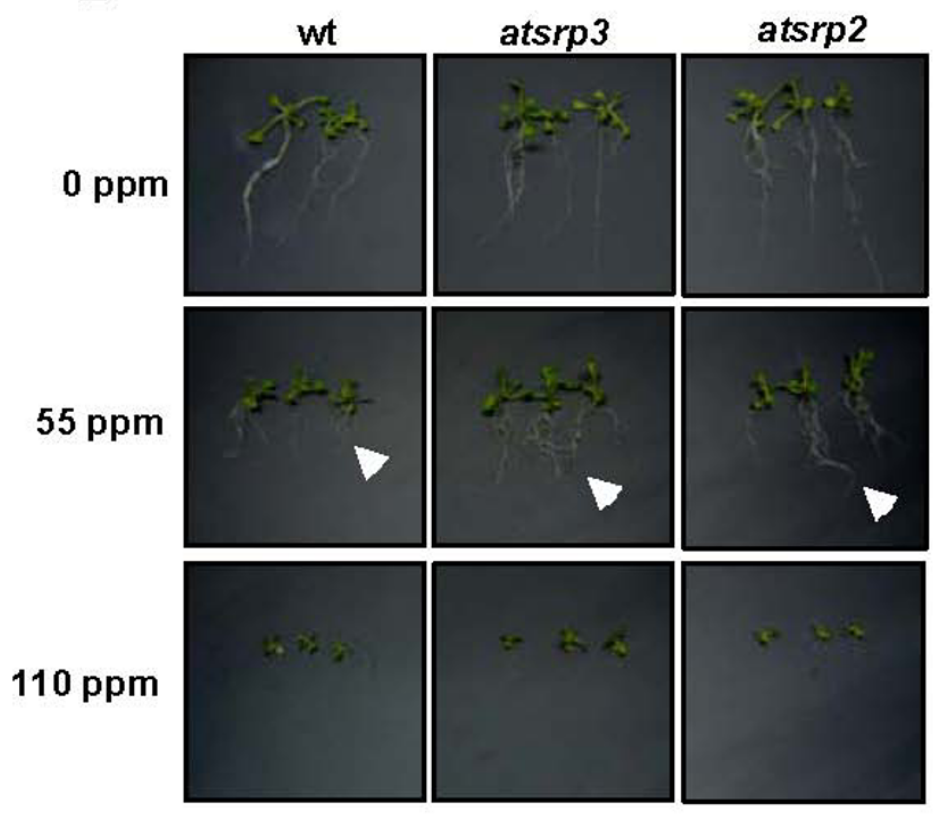

E
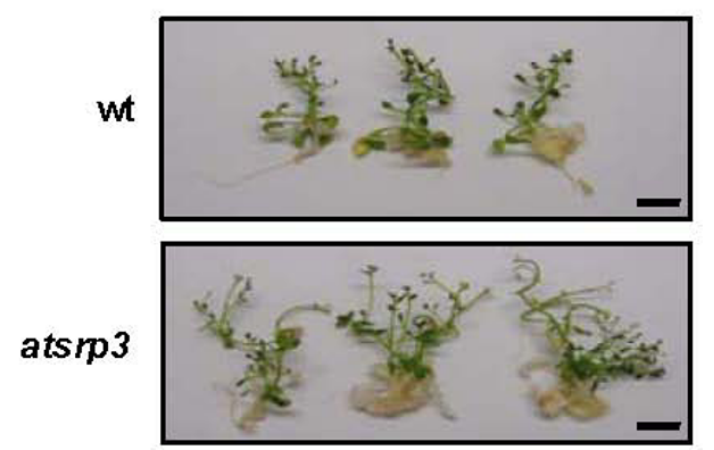

ats rp2

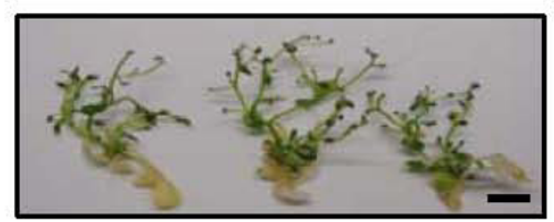

\section{Figure 4}

Responses of atsrp2 and atsrp3 mutants to MMS. B5 and half-strength MS (I/2 MS) media were used for seedling growth. (A) Vigour of atsrp2 and atsrp3 mutants compared to wild-type following treatment with MMS. Seedlings (5-d) of equal size were grown in I/2 MS liquid media containing the indicated concentrations of MMS for 2 weeks. Size bars = $10 \mathrm{~mm}$. (B-E) Seedlings (wild-type and mutants) were grown in the presence of the indicated concentrations of MMS on single plates to provide identical growth conditions. (B) Wild-type and mutant plants showing differential root lengths. Seedlings (5-d) were grown on B5 solid media. Arrows indicate root tips of mutants and wild-type plants (centre plant in each case) for comparison of root lengths. Photographs were taken on day I4. (C) Root lengths. Values are means $+/-$ SE $(n=10)$. Seedlings $(5-d)$ were grownon I/2 MS solid media. (D, E) Seedlings (2-week) were transplanted to B5 solid media containing 55 ppm MMS. (D) Leaf number per plant. Counts were made at 4 weeks after transplantation. Values are means $+/-\mathrm{SE}(\mathrm{n}=4)$. (E) Wild-type and mutant plants showing different plant sizes. Photographs were taken 4 weeks after transplantation. Size bars $=10 \mathrm{~mm}$. 
localization signal PKKK at the distal end of the RCL (Figure 1); the one-residue difference between this and the corresponding sequence in AtSRP3, PPKK, appears sufficient to retain the latter serpin in the cytosol.

\section{Responses of AtSRP2 and AtSRP3 are specific to MMS- induced DNA damage}

A test of cross-sensitivity of a collection of MMS-sensitive yeast mutants to hydroxyurea, UV light and $\gamma$-radiation found only 41 of 103 mutants showed cross-sensitivity to all three treatments [15]. Deficiency in ATM (ataxia telangiectasia mutated gene) in plants and mammals confers hypersensitivity to $\gamma$-radiation and MMS but not to UV light $[16,17]$. These and other studies show different sources of DNA damage cause distinct types of lesions and forms of cell cycle arrest. This is consistent with the differential responses of our serpin mutants (vs. wild-type) to MMS but not to UV-C or $\gamma$-radiation.

\section{Knockouts of AtSRP2 and AtSRP3 transiently reduce responses to MMS exposure}

Mutants atsrp2 and atsrp3 exposed to MMS displayed lower levels of induction of AtBRCA1, AtBARD1, AtRAD51 and AtCYCB1;1, as well as a downregulation of AtCYCD1;1, after $1 \mathrm{~d}$ compared to wild-type. Expression levels returned to wild-type levels $2 \mathrm{~d}$ after MMS exposure (Figure 6A-C). Thus AtSRP2 and AtSRP3 may be required for relatively early responses to alkylation damage. In humans, BRCA1 appears to be involved in all phases of the cell cycle [18] and BRCA1 deficiency causes abnormalities in the S-phase and G2/M checkpoint [19]. RAD51 is involved in homologous DNA repair and interacts with BRCA1 [20]; moreover, transcription of RAD51 (and AtRAD51) is highest in S-phase [21]. Yeast is most sensitive to MMS during S-phase [22]. Thus down-regulation of AtBRCA1 and AtRAD51 in the atsrp2 and atsrp3 mutants may be associated with abnormal S-phase and a defective G2/M checkpoint.

Transcripts of mitotic cyclin AtCYCB1;1 are reported to accumulate around the G2/M transition [23], whereas AtCYCD1;1 promotes not only transition through G0/G1/ $\mathrm{S}$ but also S/G2/M [24]. Cyclins (type D) are expressed throughout the cell cycle in proliferating plant tissues [25]. The CYCD1 interaction with cyclin-dependent protein kinase A (CDKA) acts at the G1/S and the G2/M boundaries in Arabidopsis [24]. These results suggest AtSRP2 and AtSRP3 may be involved in the regulation of different cell-cycle checkpoints in response to MMSinduced DNA damage. Interestingly, we detected no difference in AtATM expression between mutants and wildtype (Figure 6A-C). The Arabidopsis atm mutant is hypersensitive to $\gamma$-radiation and MMS but not to UV light [17]. The functions of AtSRP2 and AtSRP3 may be overlapping, as is found for AtATM and AtATR [26], and they may be independent of AtATM in a DNA damage-response pathway; alternatively, both serpins may act downstream of AtATM.

Regulation of the cell cycle includes mechanisms for cell cycle arrest following DNA damage to allow time for repair of the DNA [1]. Failure of these checkpoint responses leads to a build up of harmful mutations. Cell cycle arrest results in reduced rates of growth and a delay in the development of tissues. Lesions such as specific gene knockouts can interfere with the signal transduction required for the detection of DNA damage and responses including cell cycle arrest. We observed greater rates of growth of our atsrp2 and atsrp3 mutant plants exposed to MMS than that of wild-type plants given the same treatment. Thus we speculate that knockouts of these serpin genes result in de-repression of cell division following MMS treatment, thereby implicating AtSRP2 and AtSRP3 in the normal signal transduction required for the relevant checkpoint responses. It is important to note that Hefner et al. (2006) found that plant cell-cycle responses to ionizing radiation that were observed in meristematic tissues did not occur in strictly somatic tissues [27].

\section{Serpin-mediated control of proteolysis and its links to DNA damage responses}

Sequence analysis strongly suggests AtSRP2 and AtSRP3 are inhibitory serpins $[5,6]$. AtSerpin 1 can inhibit AtMC9, which is $\mathrm{Arg} / \mathrm{Lys}$ specific [11]. In contrast, we predict AtSRP2 and AtSRP3 inhibit proteinases that cleave at small residues (Figure 1). Since AtSRP2 is localized to the nucleus, its candidate targets are different than those for AtSRP3, which was localized to the cytosol (Figure 2D). Seventeen expressed genes encoding serpins with either P1 Gly or P1 Cys were recently identified from several monocots and eudicots [5]. Thus it is likely that serpins in other plant species are functional homologues of AtSRP2 and AtSRP3.

\section{Conclusion}

The inhibitory serpins encoded in the Arabidopsis genome display a variety of reactive centres, suggesting a range of target proteinases, and are differentially expressed, indicating a diversity of functions. Our results strongly suggest a new role for plant serpins, which is likely to involve inhibition of specific endogenous proteinases that target Gly and Cys residues to regulate plant responses to alkylating DNA damage. AtSRP2 and AtSRP3 are found in the cytosol and nucleus, respectively, and thus may perform distinct tasks in the signalling required for these responses. The requirement for AtSRP2 and AtSRP3 in responses to exposure to alkylating genotoxins but not to UV-C or $\gamma$-radiation provides support for distinct biochemical pathways associated with these stresses. We sug- 
A

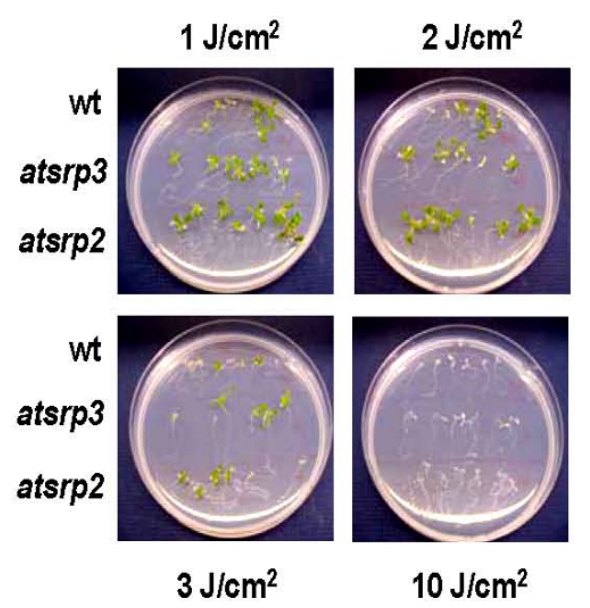

B

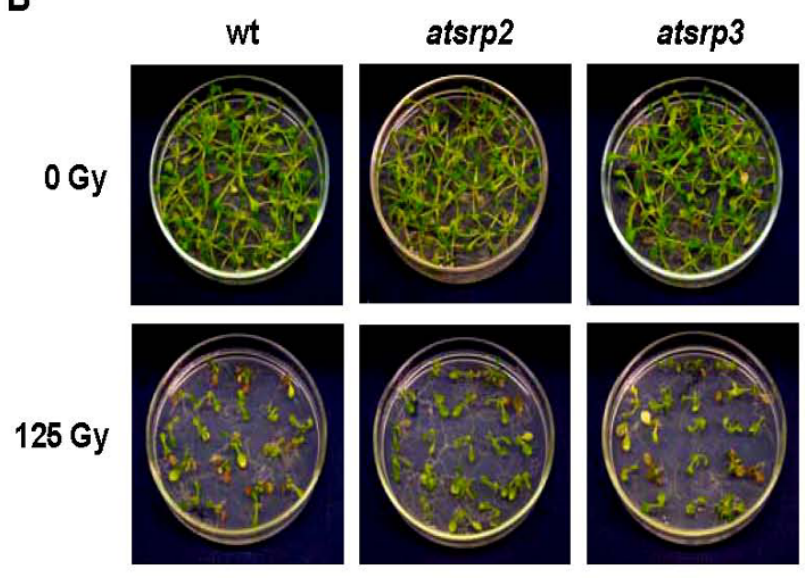

C

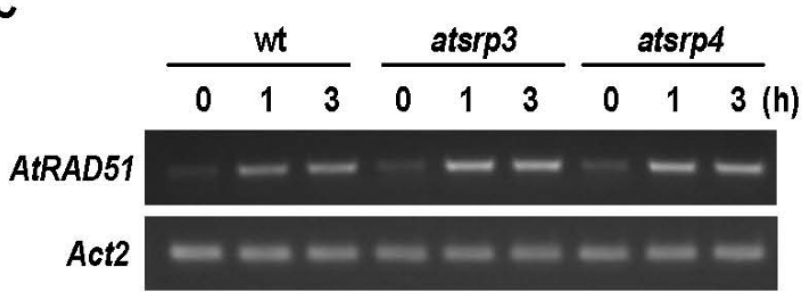

\section{Figure 5}

Response of atsrp3 and atsrp2 mutants to UV radiation and $\gamma$-radiation. (A) Seedlings (5-d) were exposed to UV radiation $\left(I, 2,3\right.$ and $10 \mathrm{~J} \mathrm{~cm}^{-2}$ ) and grown at $24^{\circ} \mathrm{C}$ for 3 weeks. Photographs were taken on day $2 \mathrm{I}$ after exposure. (B) Seedlings (5-d) were grown on B5 solid media and subjected to $\gamma$-radiation at doses of zero (control) and I25 Gy. Photographs were taken 2 weeks after irradiation. (C) Expression of DNA damage-related gene RAD5 I in whole seedlings (5-d) following exposure to $\gamma$-radiation was determined using semi-quantitative RT-PCR. 

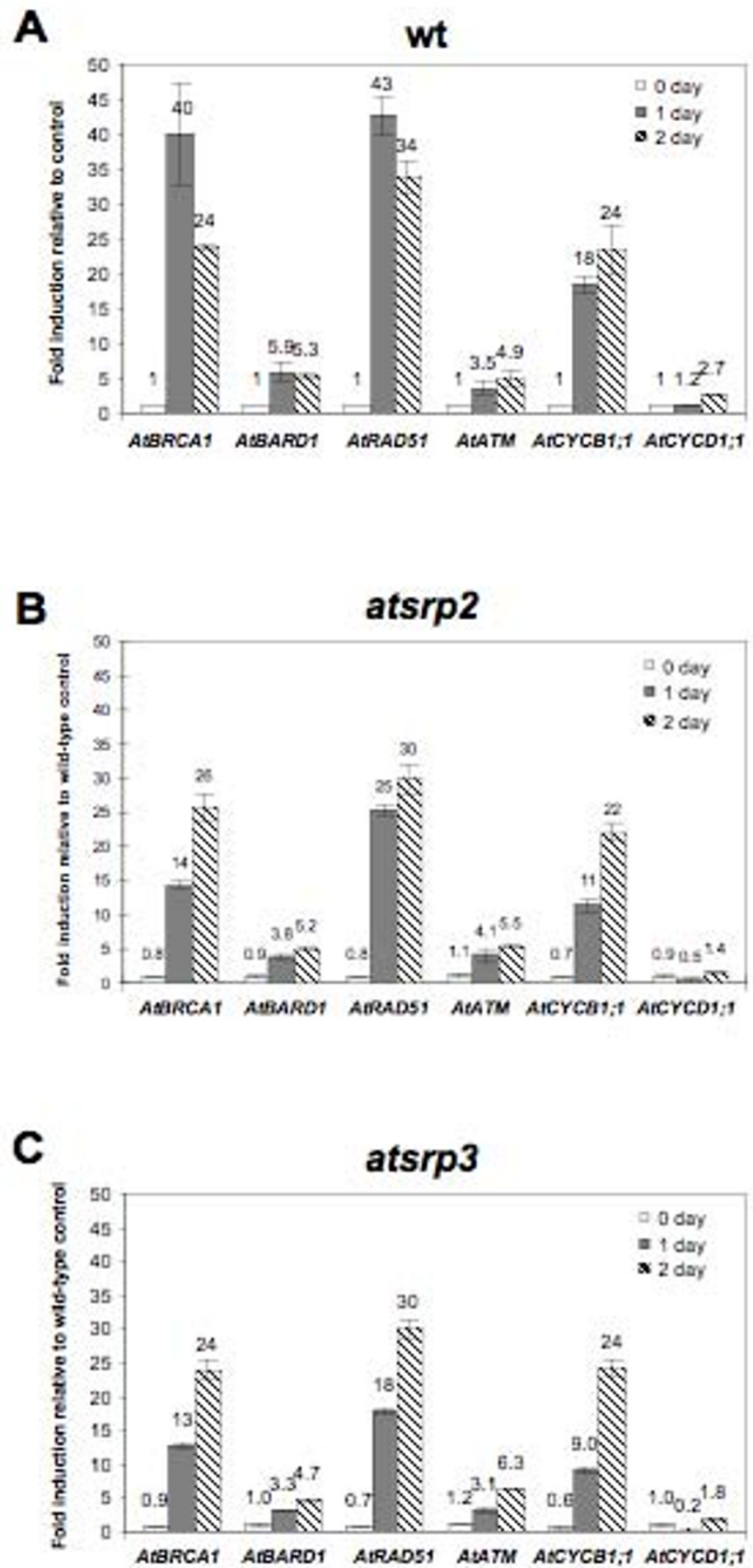

\section{Figure 6}

Expression of DNA damage- and cell cycle-related genes in wild-type and mutants atsrp2 and atsrp3 following MMS treatment. Seedlings (5-d) were transplanted to MS liquid media containing 200 ppm MMS and samples collected at the indicated time points. Expression of marker genes in (A) wild-type, (B) atsrp2 and (C) atsrp3 seedlings was determined by quantitative RT-PCR. Values are means $+/-$ SE $(n=2)$. 
gest our data have potential importance for development of crops with greater resistance to alkylating genotoxins.

\section{Methods \\ Plant materials and treatments with MMS, UV-C and - radiation}

Seeds of Arabidopsis thaliana (Col-0) were sterilized in 4\% sodium hypochlorite for $5 \mathrm{~min}$ and rinsed five times with sterilized water. Plants were grown in a chamber at $24^{\circ} \mathrm{C}$ (16 h light/8 h dark). For MMS treatment, B5 medium (Gamborg's B5 medium [28]; Gibco) containing 2\% sucrose and 1/2 MS medium (half-strength Murashige \& Skoog medium [29]; Sigma) containing 0.5\% sucrose were used. Seedlings (5-d) on sterile media (both types) were transplanted into $5 \mathrm{ml}$ of each liquid medium containing zero to $100 \mathrm{ppm}$ MMS (Sigma). Samples were incubated for $15 \mathrm{~d}$ on an orbital shaker with constant light. For measurement of root lengths, seedlings (5-d) were transplanted into each solid medium containing MMS and measurements made 15 d later. Seedlings (2 weeks old) were transplanted to media containing MMS for measurements of plant size and leaf number made 4 weeks later. Seedlings (5-d) were exposed to UV-C light (1 and $10 \mathrm{~J} \mathrm{~cm}^{-1}$ ) in open Petri dishes using a Stratalinker 2400 (Stratagene). For $\gamma$-radiation treatment, seedlings (5d) were irradiated with zero to $200 \mathrm{~Gy}$ using a ${ }^{60} \mathrm{Co}$ source and then placed into a growth chamber at $24^{\circ} \mathrm{C}$ for 3 weeks.

\section{RNA isolation and RT-PCR}

Total RNA from Arabidopsis tissues was extracted using the RNeasy Plant Mini kit (Qiagen) with 1 U RNase-free DNase (Qiagen). Reverse transcription was performed using $5 \mu \mathrm{g}$ total RNA as described [30]. cDNAs were used as templates for semi-quantitative RT-PCR and real-time RT-PCR. Primer sequences for all experiments are given in Additional File 1 (Tables one-five). RT-PCR products were cloned and sequences confirmed.

\section{Isolation of knockout mutants}

Seeds from atsrp2 and atsrp3 T-DNA insertion mutants were obtained from the Salk Institute Genomic Analysis Laboratory. For selection of lines homozygous for the TDNA insertion, primers a-f and LB were used to amplify left border-flanking and serpin DNA from genomic DNA. For confirmation of knockouts of AtSRP2 and AtSRP3 expression in atsrp2 and atsrp3 mutants, semi-quantitative RT-PCR was performed using total RNA from developing siliques.

\section{Subcellular localization}

AtSRP2 and AtSRP3 full-length cDNAs were amplified by PCR and cloned into a 326-GFP plasmid such that GFP was joined to the N-terminus of the serpins. Fusion constructs expressed under control of the cauliflower mosaic virus 35S promoter were introduced into Arabidopsis protoplasts isolated from seedlings $(10-\mathrm{d})$ by polyethylene glycol-mediated transformation. The protoplasts were incubated at $24^{\circ} \mathrm{C}$ for $24 \mathrm{~h}$. Expression of fusion proteins was observed using a Leica TCS SP2 confocal system.

\section{Abbreviations used}

MMS: methyl methanesulfonate; RCL: reactive centre loop; DSB: double-stranded break; DAPI: 4',6-diamidino2-phenylindole.

\section{Authors' contributions}

J-WA designed and performed all experimental work and helped to draft the manuscript. BJA and THR gave advice on experimental design and interpretation of results, and drafted the manuscript.

\section{Additional material}

\section{Additional file 1}

Primer sequences. Primer sequences used for isolation of homozgous TDNA insertion mutants, RT-PCR for expression analysis and cloning for subcellular localization.

Click here for file

[http://www.biomedcentral.com/content/supplementary/14712229-9-52-S1.doc]

\section{Acknowledgements}

We thank the following people from Macquarie University, Sydney: Debra Birch, Nicole Vella, Krystyna Tomsia and Hermant Bhatta for assistance with microscopy; Yu-Kyung Kim for technical assistance; Roger Hiller for advice on molecular biology; and Tom Joss for helpful discussions. We thank Anne Britt (University of California, Davis, USA) for helpful comments on the manuscript. Joon-Woo Ahn is supported by a Macquarie University Research Excellence Scholarship. Funding was through a Macquarie University Research and Development Grant.

\section{References}

I. Kimura S, Sakaguchi K: DNA repair in plants. Chem Rev 2006, 106:753-766.

2. Knight AW, Keenan PO, Goddard NJ, Fielden PR, Walmsley RM: A yeast-based cytotoxicity and genotoxicity assay for environmental monitoring using novel portable instrumentation. J Environ Monit 2004, 6:7I-79.

3. Lundin C, North M, Erixon K, Walters K, Jenssen D, Goldman AS, Helleday T: Methyl methanesulfonate (MMS) produces heatlabile DNA damage but no detectable in vivo DNA doublestrand breaks. Nucl Acids Res 2005, 33:3799-38II.

4. Rawlings ND, Morton FR, Kok CY, Kong J, Barrett AJ: MEROPS: the peptidase database. Nucl Acids Res 2008, 36:D320-325.

5. Roberts TH, Hejgaard J: Serpins in plants and green algae. Funct Integr Genomics 2008, 8: I-27.

6. Hejgaard J, Roberts TH: Plant serpins. In Molecular and Cellular Aspects of the Serpinopathies and Disorders in Serpin Activity Edited by: Silverman GA, Lomas DA. New Jersey: World Scientific; 2007:279-300.

7. Huntington JA, Read RJ, Carrell RW: Structure of a serpin-protease complex shows inhibition by deformation. Nature 2000 , 407:923-926.

8. Ostergaard H, Rasmussen SK, Roberts TH, Hejgaard J: Inhibitory serpins from wheat grain with reactive centers resembling 
glutamine-rich repeats of prolamin storage proteins - Cloning and characterization of five major molecular forms. J Biol Chem 2000, 275:33272-33279.

9. Hejgaard J: Inhibitory serpins from rye grain with glutamine as $P-1$ and $\mathbf{P}-2$ residues in the reactive center. FEBS Lett 200I, 488: $149-153$.

10. Hejgaard J, Laing WA, Marttila S, Gleave AP, Roberts TH: Serpins in fruit and vegetative tissues of apple (Malus domestica): expression of four serpins with distinct reactive centres and characterisation of a major inhibitory seed form, MdZIb. Funct Plant Biol 2005, 32:5 17-527.

II. Vercammen D, Belenghi B, Cotte B van de, Beunens T, Gavigan JA, De Rycke R, Brackenier A, Inze D, Harris JL, Van Breusegem F: Serpin I of Arabidopsis thaliana is a suicide inhibitor for Metacaspase 9. J Mol Biol 2006, 364:625-636.

12. Yoo BC, Aoki K, Xiang Y, Campbell LR, Hull RJ, Xoconostle-Cazares B, Monzer J, Lee JY, Ullman DE, Lucas WJ: Characterization of Cucurbita maxima phloem serpin-I (CmPS-I) - A developmentally regulated elastase inhibitor. J Biol Chem 2000, 275:35|22-35|28.

13. Schechter I, Berger A: On the size of the active site in proteases. I. Papain. Biochem Biophys Res Commun 1967, 27:157-162.

14. Baerenfaller K, Grossmann J, Grobei MA, Hull R, Hirsch-Hoffmann M, Yalovsky S, Zimmermann P, Grossniklaus U, Gruissem W, Baginsky S: Genome-scale proteomics reveals Arabidopsis thaliana gene models and proteome dynamics. Science 2008, 320:938-94I.

15. Chang M, Bellaoui M, Boone C, Brown GW: A genome-wide screen for methyl methanesulfonate-sensitive mutants reveals genes required for $\mathbf{S}$ phase progression in the presence of DNA damage. Proc Natl Acad Sci USA 2002, 99:16934-16939.

16. Gasch AP, Huang M, Metzner S, Botstein D, Elledge SJ, Brown PO: Genomic expression responses to DNA-damaging agents and the regulatory role of the yeast ATR homolog Meclp. Mol Biol Cell 200I, I 2:2987-3003.

17. Garcia V, Bruchet H, Camescasse D, Granier F, Bouchez D, Tissier A: AtATM is essential for meiosis and the somatic response to DNA damage in plants. Plant Cell 2003, 15:1 19-132.

18. Deng CX: BRCAI: cell cycle checkpoint, genetic instability, DNA damage response and cancer evolution. Nucl Acids Res 2006, 34:1416-1426.

19. Xu X, Weaver Z, Linke SP, Li C, Gotay J, Wang XW, Harris CC, Ried $T$, Deng CX: Centrosome amplification and a defective G2-M cell cycle checkpoint induce genetic instability in BRCAI exon II isoform-deficient cells. Mol Cell 1999, 3:389-395.

20. Pellegrini L, Yu DS, Lo T, Anand S, Lee M, Blundell TL, Venkitaraman $A R$ : Insights into DNA recombination from the structure of a RAD5 I-BRCA2 complex. Nature 2002, 420:287-293.

21. Doutriaux MP, Couteau F, Bergounioux C, White C: Isolation and characterisation of the RAD5I and DMCI homologs from Arabidopsis thaliana. Mol Gen Genet I998, 257:283-29I.

22. Tercero JA, Diffley JF: Regulation of DNA replication fork progression through damaged DNA by the Mecl/Rad53 checkpoint. Nature 200I, 4 I 2:553-557.

23. Doerner P, Jorgensen JE, You R, Steppuhn J, Lamb C: Control of root growth and development by cyclin expression. Nature 1996, 380:520-523.

24. Koroleva OA, Tomlinson M, Parinyapong P, Sakvarelidze L, Leader D, Shaw P, Doonan JH: CycDI, a putative GI cyclin from Antirrhinum majus, accelerates the cell cycle in cultured tobacco BY2 cells by enhancing both GI/S entry and progression through S and G2 phases. Plant Cell 2004, 16:2364-2379.

25. Sorrell DA, Combettes B, Chaubet-Gigot N, Gigot C, Murray JA Distinct cyclin $D$ genes show mitotic accumulation or constant levels of transcripts in tobacco bright yellow-2 cells. Plant Physiol 1999, I 1 9:343-352.

26. Culligan KM, Robertson CE, Foreman J, Doerner P, Britt AB: ATR and $A T M$ play both distinct and additive roles in response to ionizing radiation. Plant J 2006, 48:947-96I.

27. Hefner $E$, Huefner $N$, Britt $A B$ : Tissue-specific regulation of cellcycle responses to DNA damage in Arabidopsis seedlings. DNA Repair 2006, 5: 102-1 I0.

28. Gamborg OL, Miller RA, Ojima K: Nutrient requirements of suspension cultures of soybean root cells. Exp Cell Res 1968, 50:151-158.
29. Murashige T, Skoog F: A revised medium for rapid growth and bioassays with tobacco tissue cultures. Physiol Plant 1962, I5:473-497.

30. Kim M, Ahn JW, Jin UH, Choi D, Paek KH, Pai HS: Activation of the programmed cell death pathway by inhibition of proteasome function in plants. J Biol Chem 2003, 278:19406-19415.
Publish with Bio Med Central and every scientist can read your work free of charge

"BioMed Central will be the most significant development for disseminating the results of biomedical research in our lifetime. "

Sir Paul Nurse, Cancer Research UK

Your research papers will be:

- available free of charge to the entire biomedical community

- peer reviewed and published immediately upon acceptance

- cited in PubMed and archived on PubMed Central

- yours - you keep the copyright 